\title{
Obtaining resistance parameters in iron ore tailing from field (SPT and CPTu) and laboratory tests
}

\author{
Giovani Costa ${ }^{1, *}$, and Lúcio Flávio Villar ${ }^{2}$. \\ ${ }^{1}$ Chammas Engenharia, Geotechnical Field Investigation Department, 30.360-330 Belo Horizonte, Brazil \\ ${ }^{2}$ Universidade Federal de Minas Gerais, Geotechnical and Transport Department, 31.270-901 Belo Horizonte, Brazil
}

\begin{abstract}
Understanding the behaviour of materials resulting from mineral exploration is important in the current scenery of exploration and processing, with high mining waste generation and consequent catastrophic disasters. In this context, this paper presents the results of a geotechnical investigation carried out at an iron ore tailing in Minas Gerais - Brazil aimed at obtaining the shear strength parameters. The methodology is based on a large bibliographic review of field and laboratory tests, and based on obtaining geotechnical correlations, followed by both field and laboratory data analysis resulting from CPTu, SPT and laboratory tests (triaxial). Geotechnical parameters of the presented iron ore tailing enhance knowledge of this material disposed in dams, whose stability and integrity are directly related to the effect of these parameters interaction and mobilization.
\end{abstract}

\section{Introduction}

The mining sector is part of Minas Gerais' history. This fact is proven by its own name. Currently, mining is still an economic activity of great importance in the state, which has more than 300 mines in operation, 57 of which are included in the 200 largest in the country, according to the Brazilian Mining Institute - IBRAM (2017) [1].

According to Zhouri (2017) [2], mining activity can cause serious impacts on the environment and people's lives. It can damage the water, soil and air, as well as develope diseases in people who live close to mining areas or who are exposed to them by their jobs.

Presotti (2002) [3] addresses the use of mining waste as the main material in the construction of dams. However, this type of material has characteristics that vary, for example, according to its processing method, the variability of the mining fronts and the way they are arranged. Thus, stability problems in structures made of tailings are increasingly common due to their mechanical behaviour not being linked to a well-defined pattern.

Chammas (2018) [4] adds that tailings dams are inseparable structures from mining and that they have been designed increasingly larger and more voluminous. Since most of the time dams are built with the upstream method, they take advantage of the tailings deposited in the form of a beach as a component of the elevation. Therefore, it is necessary to maintain a geotechnical investigation and monitoring plan to control the tailings behaviour and guarantee the structural safety of the dams, throughout their operational life and deactivation.
In this context, it is important to know more and more about the characteristics of the tailings generated after mineral treatment and processing. Understanding their behaviour and how they interact with the environment can be crucial in preventing environmental disasters generated by mining activity. The works of Espósito (2000) [5], Presotti (2002) [3], Pereira (2005) [6], Motta (2008) [7] and Rezende (2013) [8] make great contributions to better understanding iron ore tailings.

When it comes to the unsaturated soil mechanics, Fredlund and Rahardjo (1993) [9] addresses tailing dams as one of the great geotechnical constructions the unsaturated science can be well applied. Especially in Brazilian dams, where the tropical weather results in long periods of drought, making the unsaturated condition quite recurrent.

The unsaturated soil analysis on tailing dams is also proved to be important by Carvalho et al. (2015) [10]. According to their work, the construction method of dams uses compacted soil, so the embankment tends to stay unsaturated in several parts. This condition is reinforced when there are internal drainage systems. In this case, shear resistance parameters are directly influenced by suction. Therefore, stability conditions are more realistic when the unsaturated soil aspect is considered.

The study developed in this paper intends to present the results of a geotechnical investigation campaign carried out on iron ore tailings and to show the shear strength parameters obtained directly and/or by correlations from CPTu, SPT and triaxial testing. Then, a comparison is made with the results obtained by other researchers who have also studied iron ore tailings in

\footnotetext{
* Corresponding author: giovani.costa@ chammasengenharia.com.br
} 
other locations in Minas Gerais. The waste studied here belongs to a specific company in the steel industry that operates in conjunction with the mining industry. Even though the unsaturated soil mechanics is not applied here, its importance is highlighted when it comes to tailing dams.

\subsection{Objectives}

The purpose of this article is to present the results of field (SPT and CPTu) and laboratory tests carried out on iron ore tailings from a specific company in the steel industry, establishing shear strength parameters and observing the convergence of the results obtained for the different types of tests, comparing them with results obtained by other researchers for the same material.

It is also the objective of this research to discuss the obtained results, to draw conclusions about them and to propose aspects for future research and improvement for this study.

\section{Literature review}

\subsection{Cone penetration test (CPT)}

The Cone Penetration Test in situ, better known as CPT, consists of pushing a conical tip into the ground, continuously and at a constant speed. According to ABNT (1991) [11], through NBR 12069, in this process the reaction of the cone to the tip resistance and to the lateral friction is measured. According to Robertson and Cabal (2015) [12] it is also possible to perform measurements of pore pressures with a special type of cone, the piezocone.

For correct execution of the test, Clayton et al. (1995) [13] affirm that the pushing speed should be monitored and maintained at $2+/-0.5 \mathrm{~cm} / \mathrm{s}$. The conical tip used must have a $60^{\circ}$ apex and $10 \mathrm{~cm}^{2}$ of face area (diameter of $35.7 \mathrm{~mm}$ ). The lateral part, reserved for measuring the friction of the cone to the ground, must be $150 \mathrm{~cm}^{2}$, the diameter of which is the same as for the conical tip.

According to Schnaid and Odebrecht (2012) [14], for the CPT, the information obtained is the tip resistance (qc) and the lateral friction (fs). When using the piezocone, information about pore pressure $(\mathrm{u})$ can also be obtained. In addition, during the execution, two other types of complementary tests can be performed: dissipation and seismic tests. With the information provided, it is possible to obtain a series of correlations that result in different important geotechnical parameters and predictions about the stratigraphy of the prospected soil.

\subsection{Standard penetration test (SPT)}

The Standard Penetration Test (SPT) is the test mostly used in soil investigations in the Brazilian and world scenario. As reported by Afonso (2016) [15], SPT is a dynamic test in which a standardized sampler is driven into the bottom of a borehole, using a $65 \mathrm{~kg}$ hammer that falls from a height of $0,75 \mathrm{~m}$. The Brazilian Standard that rules the test, NBR 6484 (2001) [16], lists the three purposes of an SPT, being them to determine the types of soil according to the depths they occur, the groundwater table, and the resistance to soil penetration every meter.

Mayne et al. (2002) [17] describe the SPT test as the setting of a sampling tube in previously marked locations. The number of blows are registered while the sampler enters $45 \mathrm{~cm}$ into the ground. The increments are made every $15 \mathrm{~cm}$, so that the number of blows delivered to the system at each $15 \mathrm{~cm}$ section is registered. The number of blows given to advance the final $30 \mathrm{~cm}$ of the sampler results in an extremely important index for the interpretation of the test. This is the Nspt, the index of resistance to SPT penetration, whose purpose is to classify the soil according to its consistency/density. From the number provided by the average resistance given by Nspt it is possible to establish correlations between the most diverse geotechnical parameters.

\subsection{Laboratory tests}

According to Das (2011) [18], there are currently several types of laboratory tests that can determine soil shear resistance parameters. As an example, the following can be mentioned: direct shear tests, simple shear tests, ring shear tests, triaxial tests;

The triaxial compression test, according to Das (2011) [18], can be considered one of the most reliable ways of obtaining soil shear strength parameters. Rigueira et al. (2015) [19] add that this is the most complete test when it comes to determining these parameters, being widely used when there is a need to know the pore-pressures values developed during the rupture of the test specimen. By performing the test for different loads and in different specimens, it is possible to obtain the corresponding Mohr circles and the respective resistance envelope.

\subsubsection{Cu triaxial tests (consolidated undrained)}

Pinto (2006) [20] describes this test as the one in which the confining tension is applied and the corresponding pore pressure is allowed to dissipate. However, the loading phase is done axially without drainage, configuring the undrained step of the test. As a result, there is the parameter of undrained resistance.

\subsection{Previous researches related to iron ore tailings}

Presotti (2002) [3] says that several geotechnical tests have been done on iron ore tailings in order to determine the shear strength parameters and to obtain correlations for other geotechnical parameters.

Espósito (2000) [5] carried out a study in the Monjolo and Xingu Piles (State of Minas Gerais - Brazil) and, based on triaxial laboratory tests, established parameters that characterize the iron waste. By performing the CD triaxial, the value of $0 \mathrm{kPa}$ was found in all tested samples for the effective cohesion intercept. For effective friction angle values, the range of $32.40^{\circ}-41.50^{\circ}$ was found. For the $\mathrm{CU}$ triaxial tests performed, the same null value for 
effective cohesion was found, and the range for the effective friction angle was $24.40^{\circ}-39.90^{\circ}$.

Motta (2008) [7] also developed studies about iron ore tailings. CD triaxial tests were performed and the value of $36^{\circ}$ for the effective friction angle parameter was established. The study was carried out at the Germano Dam, in the city of Mariana (State of Minas Gerais Brazil).

Presotti (2002) [3] carried out studies at the Água Limpa Mine (State of Minas Gerais - Brazil), located in Rio Piracicaba. His researches showed that this material appears to be quite sandy. In addition, he determined the friction angle value for 4 different samples. The range obtained for this parameter was $35^{\circ}-36^{\circ}$.

Pereira (2005) [6] studied the iron ore waste disposed in dams for several locations of the iron ore quadrilateral of Minas Gerais. He conducted several triaxial CU tests in mines located in Mariana, Ouro Preto and Itabira (State of Minas Gerais - Brazil), with the confining stresses of 50,100 and $200 \mathrm{kPa}$. The results for the friction angle parameter ranged from $32^{\circ}-39^{\circ}$.

Rezende (2013) [8] also contributed to the studies on iron ore tailings, carrying out his study in Mariana, at the Fundão Dam (State of Minas Gerais - Brazil). 4 CD tests were performed on samples taken from the tailings beach. The values for friction angle varied from $32^{\circ}$ to $35^{\circ}$.

All authors mentioned in this section obtained a null value for the effective cohesion intercept of iron ore tailings. Also, all of the above studies were developed in Minas Gerais, Brazil.

Passos (2009) [21] contributes to the study of iron ore tailings, distinguishing them into two types of tailings, one with a finer tendency and the other more granular. The latter is the one used for raising dams. Its particle size varies from sand to colloid, and the sandy fraction is irregular due to crushing and grinding processes.

Espósito (2000) [5] shows that the use of granular waste as a building material in dams has been shown to be increasingly advantageous. However, for that, one must have strict control of its use. Therefore, studies and analysis of the geotechnical parameters that characterize these materials are crucial.

\subsection{Obtaining resistance parameters through CPTu, SPT and triaxial laboratory tests}

\subsubsection{Undrained shear strength}

According to Filho (2010) [22] the undrained shear resistance of soils should not be taken as an intrinsic characteristic. In fact, it may vary according to the rupture mode, the soil anisotropy, the history of stresses and the deformation speed. Studies by Clayton et al. (1995) [13], Robertson and Cabal (2015) [12], Schnaid and Odebrecht (2012) [14], Marangon (2006) [23], Terzaghi and Peck (1967) [24], among others, show correlations for estimating Su from CPTu and SPT. When in laboratory, the undrained shear resistance parameter is obtained by performing UU triaxial tests.

\subsubsection{Friction angle}

For the Piezocone Penetration Test (CPTu), Kulhaway and Mayne (1990) apud Robertson and Cabal (2015) [12] suggested a correlation for cementless, clean and angular sands as shown below. Silva (2014) [25] made use of the following equation to obtain the effective friction angle in his study on mining tailings.

$$
\Phi^{\prime}=17.6+11 * \log (Q t n)
$$

where $\phi^{\prime}$ is the effective friction angle and Qtn the normalized tip resistance.

According to Schnaid and Odebrecht (2012) [14], cone tip resistance values can be used to estimate the friction angle for granular soils.

As for the Standard Penetration Test (SPT), according to Schnaid and Odebrecht (2012) [14], an established common practice is the correlation between Nspt and the friction angle $\left(\phi^{\prime}\right)$ of granular soils.

Some of the most used correlations for obtaining soil friction angle based on SPT results are shown below. Equations 2, 3 and 4 were proposed by Teixeira and Godoy (1996) [26], Muromachi (1974) [27] and Hatanaka and Uchida (1996) [28] respectively.

$$
\begin{gathered}
\Phi^{\prime}=15+\operatorname{sqrt}(20 * N s p t) \\
\Phi^{\prime}=20+3.5 * \operatorname{sqrt}(N s p t) \\
\Phi^{\prime}=20+\operatorname{sqrt}(15.4 * N s p t, 60)
\end{gathered}
$$

being $\phi$ ' the effective friction angle and Nspt,60 the Nspt value corrected for an energy of $60 \%$.

\subsubsection{Cohesion}

The obtainance of the cohesion intercept in CPTu tests is reduced to undrained resistance, since the test is mostly indicated and applied on soft soils, so that when performed in clay deposits, the test speed of $2 \mathrm{~cm} / \mathrm{s}$ ensures that it is being carried out in undrained conditions.

As for the SPT test, Marangon (2006) [23] established empirical correlations between the test and cohesion parameters for clays and clayly soils. For sands and sandy soils, the considered value was $0 \mathrm{kPa}$.

\section{Methodology}

The performed geotechnical investigation is summarized by 4 CPTu tests, 16 drill holes for SPT and triaxial tests in 3 undisturbed samples (blocks).

The entire geotechnical campaign was carried out by the engineering company Chammas Engenharia, which provided the equipment for execution and allowed the results to being used in the present paper. Due to confidential matters, the location of the geotechnical investigations presented here will not be disclosed.

\subsection{Drilling plan}

In order to locate the proposed holes, Figure 1 shows a sketch of the drilling plan carried out in the studied area. 
The SPs holes 8 to 16 were not initially planned, therefore they are not shown in Figure 1. However, these holes location was intermediate to the SPs 1 to 7 , which have all been executed in the same area and in the same dam. Figure 2 shows a sketch that situates all the holes drilled for SPT drilling, CPTu tests and the removal of the undisturbed samples (blocks). The holes SP-05, 06, 07 and 15 are highlighted because they are located on top of the initial dam.

It is observed that the layout of the $4 \mathrm{CPTu}$ 's tests matches the layout of the SPs 1 to 4 . In addition to that, undisturbed soil samples were also taken at strategic points and close to the SPT and CPTu tests performed.

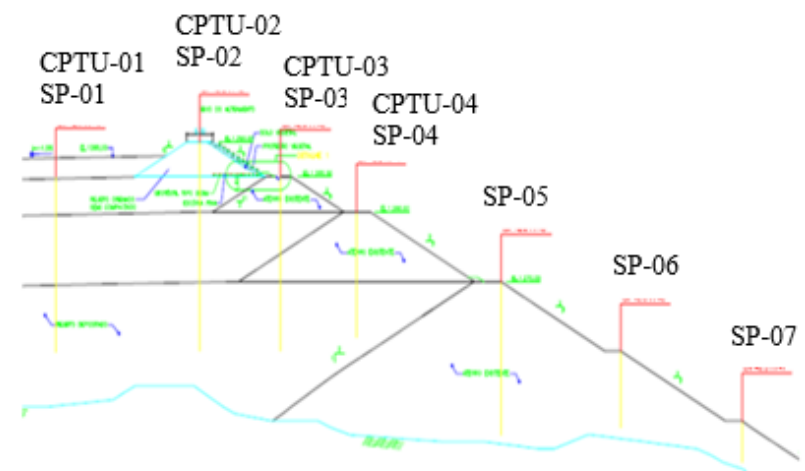

Fig 1. Location sketch of drilling holes SPs 1-7 and CPTu 1-4

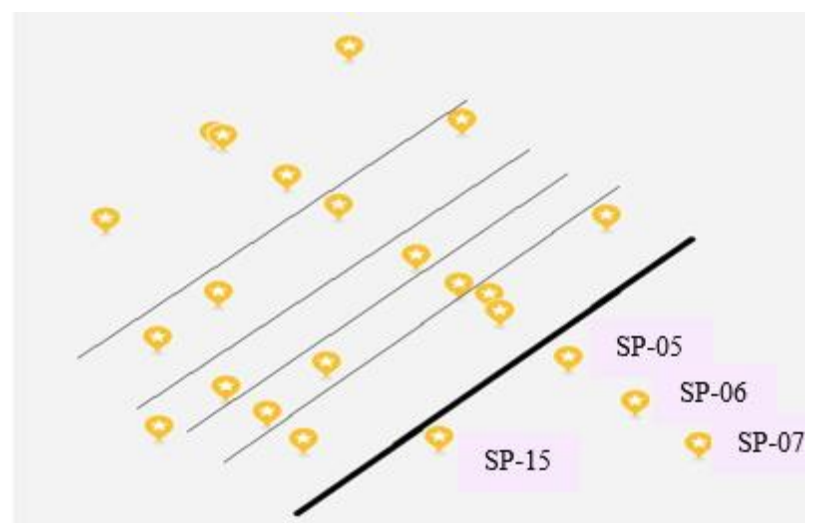

Fig. 2. Location sketch of drilling holes for the geotechnical investigation

\subsection{Used equipments}

To perform the CPTu tests, a 1-ton static penetrometer was used. Its reaction power is provided by anchoring the equipment properly to the ground. The pushing of the cone is done centrally on the machine, with the addition of 1 meter rods until the desired depth. The monitoring of information in real time can be seen in a datalogger coupled to the drilling machine. To guarantee the perfect execution of the test, it is important that the equipment is rightfully levelled.

On the other hand, the SPTs were carried out with the percussion tripod. It is the standard test procedure, in which the $65 \mathrm{~kg}$ hammer is lifted to a height of $75 \mathrm{~cm}$, dropping it in a free fall regime in order to nail the standard sampler and count the number of blows given.
As for the laboratory procedures, the gradation test was performed in standard test sieves, with openings of 2", 1 1/2", 1", 3/4", 3/8", No. 04 , No. 10 , No. 16, No. 30 , No. 40, No. 50, No. 100 and No. 200. In addition, sedimentation was carried out in a suitable beaker with the use of hexametaphosphate as a dispersant. The speeds for causing the deformations were $0.09 \mathrm{~mm} / \mathrm{min}$ and 0.11 $\mathrm{mm} / \mathrm{min}$. For undisturbed samples, 3 CUSat triaxial tests were performed, each with 4 specimens, varying the stresses from 50 to $400 \mathrm{kPa}$, with increments of twice the previously applied tension.

\subsection{Tests executed}

\subsubsection{CPTu}

During the geotechnical investigation campaign, 4 special piezocone tests were performed, totalizing the amount of 73.57 linear meters prospected, in addition to 13 dissipation tests.

After saturation and assembly of the piezocone, the tests were started. Prior to its beginning, the readings defined as "zero" were checked. This reading is taken with the piezocone still suspended, a few meters above its drilling point. After the initial calibration, the pushing of the cone is initiated, always maintaining the speed of 2 $\mathrm{cm} / \mathrm{sec}$. The available rods, with a total length of 1 meter, are coupled to the system according to the need for pushing deeper.

The results of CPTu are displayed continuously, through graphs, simultaneously with the test execution.

\subsubsection{SPT}

All the drilled holes had their first meter dug with the use of a hand auger. Then, the standard SPT sampler was inserted. The way used to divide the three $15 \mathrm{~cm}$ sections was to draw a simple scratch with chalk on the sampler.

After advancing $45 \mathrm{~cm}$ with the sampler, the other 55 $\mathrm{cm}$ were removed using a spiral auger. Alternatively, the washing method was used. The SPT striking procedure was repeated up to the depth in which the test was considered impenetrable by normative criteria.

\subsubsection{Laboratory tests}

For the campaign of laboratory tests, 3 undisturbed samples were removed.

The gradation tests were performed according to ABNT NBR 7181/2016.

The triaxial tests were all done fast, saturated, consolidated, undrained, and with pore pressure measurement (CUSat). The specimens' saturation process occurred by percolation followed by the effect of back pressure stages in order to reach the pore pressure parameter $\mathrm{B} \geq 0.96$. However, the back pressure was limited to a maximum of $400 \mathrm{kPa}$ and then the Skempton parameter was verified. $\mathrm{B} \geq 0.96$ could not be reached for $400 \mathrm{kPa}$ backpressures. Therefore, in order to maintain the samples integrity, no more back pressure stages were 
applied. Finally, the specimens were consolidated at the abovementioned confining stresses $(50,100,200$ and 400 $\mathrm{kPa}$ ). All tests were done in controlled strain apparatus, with a strain rate of $0.09 \mathrm{~mm} / \mathrm{min}$ for sample 3 and 0.11 $\mathrm{mm} / \mathrm{min}$ for samples 1 and 2, taking the strain to $20 \%$.

\section{Results}

\subsection{Particle-size distribution analysis}

Figure 3 shows the result of the gradation tests performed on the 3 undisturbed samples. From the laboratory analysis, it was found that the researched soil contains approximately $53.6 \%$ of fine sand, $42.6 \%$ of silt and $3.5 \%$ of clay. Complementary to the test, the material was described as silty sand with traces of light brown clay, according to the unified classification of NBR 7250/1982.

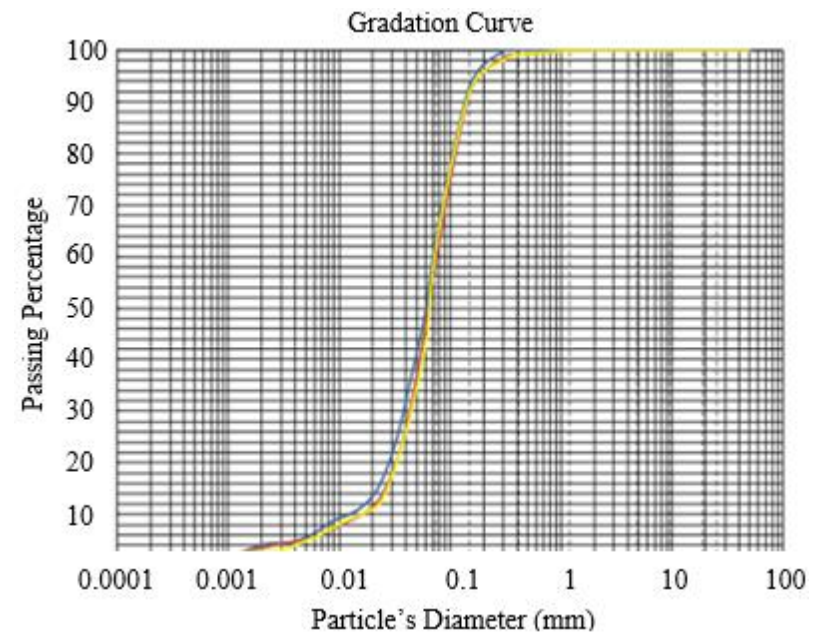

Fig. 3. Granulometric curve for the samples tested in the laboratory

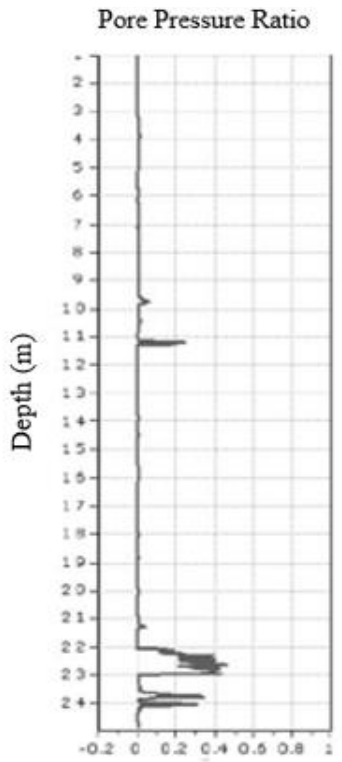

$\mathrm{Bq}$
Pore Pressure Ratio

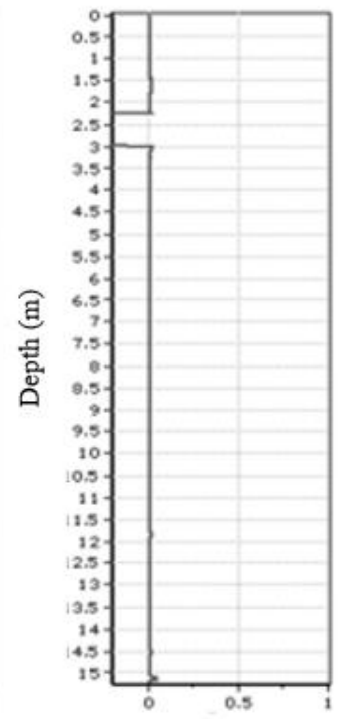

$\mathrm{Bq}$

\subsection{Undrained shear strength (su)}

\subsubsection{CPTu}

One of the several results in the CPTu test is called "pore pressure ratio". This data is obtained by the quotient of the variation of pore-pressure and the tip resistance, an index called "Bq". For $0<\mathrm{Bq}<0.4$, Sosnoski (2016) [29] states that the material has a sandy behaviour and the test has a drained characteristic, so that the parameters found will all be in their effective form. Thus, analyzing Figure 4, the drained behaviour of the test is noticeable. Therefore, the value of $\mathrm{Su}$ was not calculated for CPTu tests.

\subsubsection{SPT}

$\mathrm{Su}$ formulas based on SPT are only for clay soils of different plasticity.

The sentence above reinforces the fact that parameters of undrained shear resistance are linked to the conditions in which the tests are performed (in an undrained regime), which is not the present case. Once sandy granulometry is detected for the studied tailings and the water level is determined as dry by the drilling process, it is expected that the test will be drained. Therefore, the $\mathrm{Su}$ parameter will not be calculated by SPT correlations.

\subsubsection{Cu triaxial tests (consolidated undrained)}

The triaxial tests performed had the objective of estimating the effective soil resistance parameters. In this test, there is the consolidation phase of the specimen, followed by the loads that are carried out in a non-drained manner with poropressure development monitoring. Thus, for Su determination, the UU triaxial test would have to have been performed.

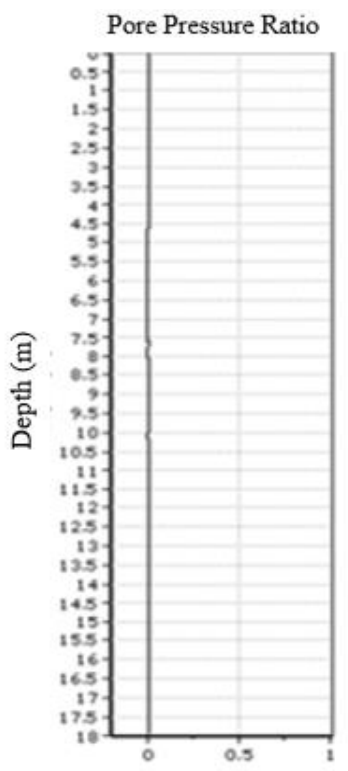

$\mathrm{Bq}$

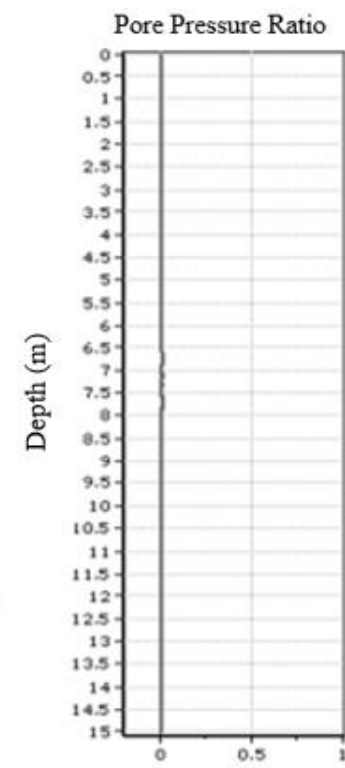

$\mathrm{Bq}$

Fig. 4. Bq index for CPTu-01 to 04 . 

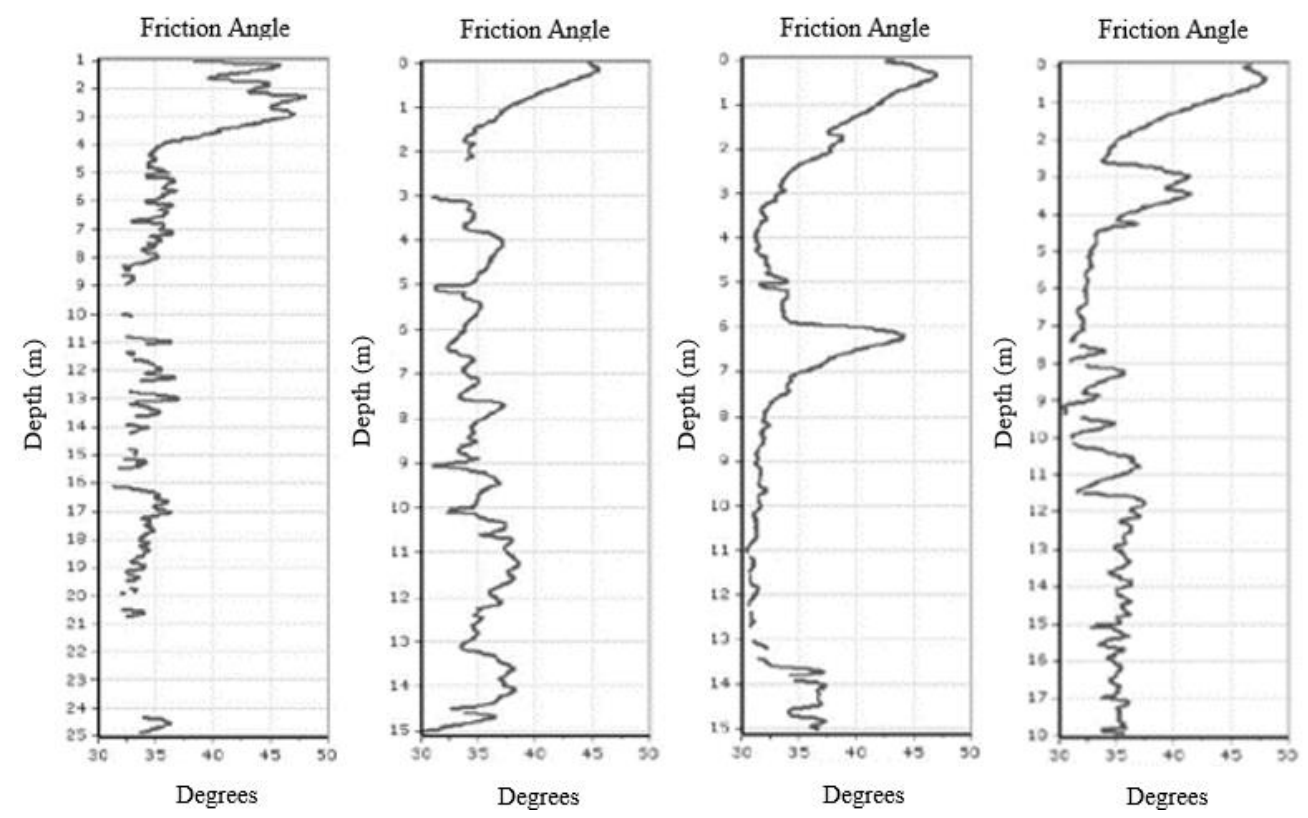

Fig. 5. Friction angle profile for all CPTu executed

\subsection{Friction angle}

\subsubsection{CPTu}

The $\mathrm{CPTu}$ results analysis was based on equation 1 proposed by Kulhaway and Mayne (1990) apud Robertson and Cabal (2015) [12]. Figure 5 shows the results for the friction angle parameter calculated in each case. The average Qtn values used were 53.90; 48.87; 54.61 and 62.74 for each of the four holes, respectively.

The average, maximum and minimum values registered for the effective friction angle of $\mathrm{CPTu}-01,02$, 03 and 04 are the ones shown in Table 1 below.

Table 1. Effective friction angle obtained from CPTu tests

\begin{tabular}{l|c|c|c} 
& Average $\left({ }^{\circ}\right)$ & Maximum $\left({ }^{\circ}\right)$ & Minimum $\left({ }^{\circ}\right)$ \\
\hline CPTU-01 & 36.25 & 48 & 31 \\
\hline CPTU-02 & 35.71 & 46 & 30 \\
\hline CPTU-03 & 35.56 & 47 & 30 \\
\hline CPTU-04 & 35.48 & 48 & 30
\end{tabular}

After each test' separately analysis, the average value for the effective friction angle of all CPTu was $35.50^{\circ}$.

\subsubsection{SPT}

From the data collected in the drilling reports for holes SPT-01 to SPT-16, it was possible to estimate the friction angle and the cohesion of the studied iron ore tailings. The analysis of the SPT tests and the obtained values for friction angle are shown in Figures 6,7 and 8 below. Equations 2, 3 and 4 were used in this analysis.

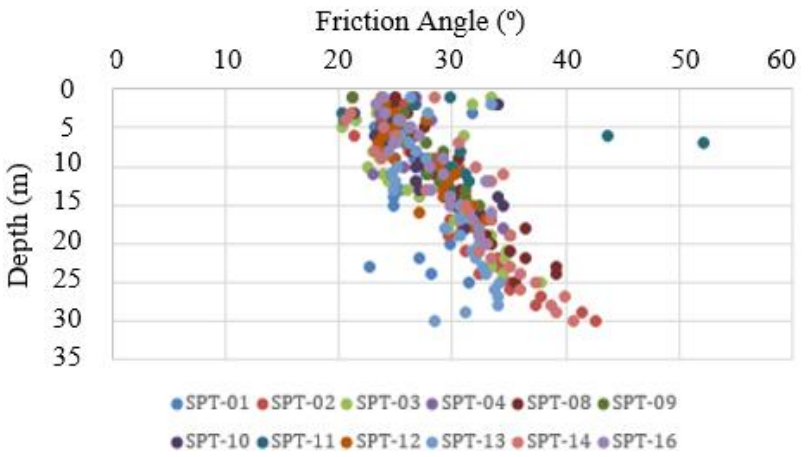

Fig. 6. Friction angle $x$ depth - Equation 2

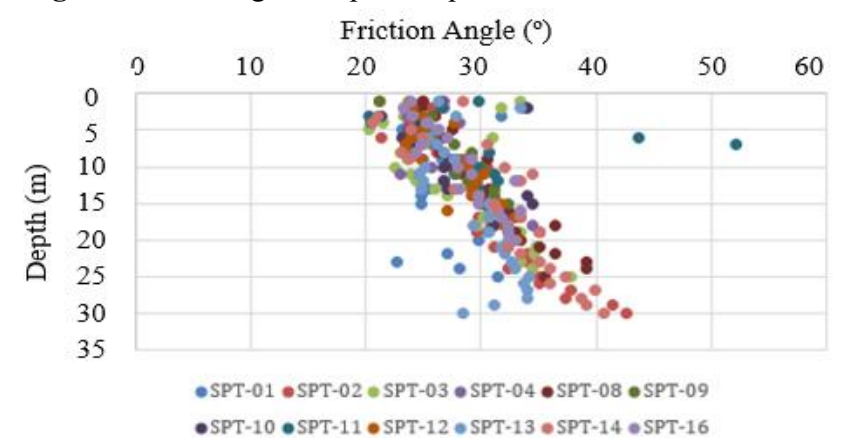

Fig. 7. Friction angle $x$ depth - Equation 3

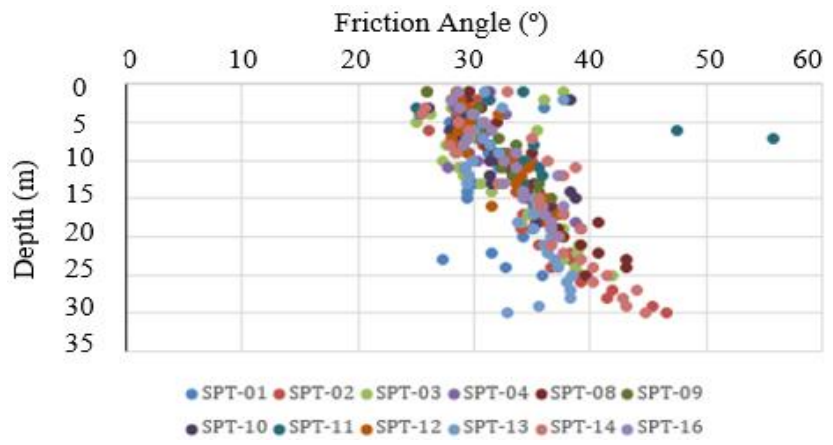

Fig. 8. Friction angle $\mathrm{x}$ depth - Equation 4 
The analysis shows an increasing trend with depth for the studied parameter. This bias is confirmed by the formulations that take into account a greater friction angle for higher SPT.

\subsubsection{Cu triaxial tests (consolidated undrained)}

From the data obtained on the triaxial tests, it was possible to trace the most adequate resistance envelope and to obtain values for the friction angle parameter, as shown in Figure 9 below.

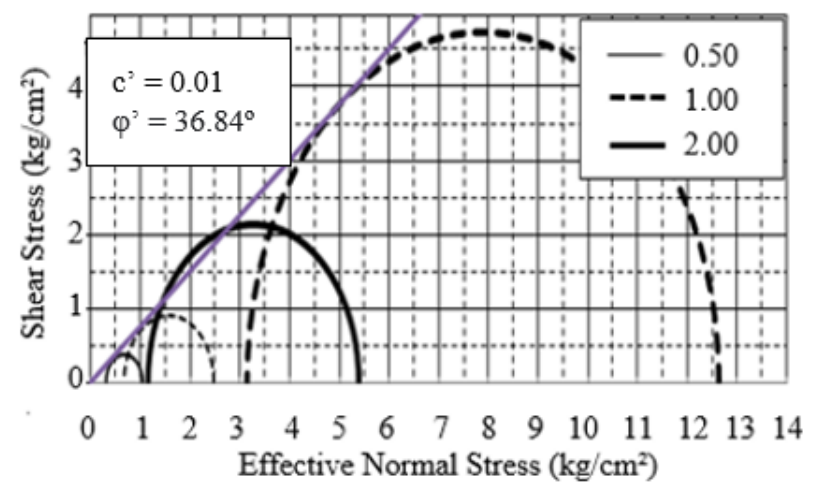

Fig. 9. Triaxial test performed in one of the undisturbed samples (sample 1).

The resistance envelope was drawn for the three undisturbed samples. The results are shown in Table 2 .

Table 2. Effective friction angle obtained from cu triaxial tests

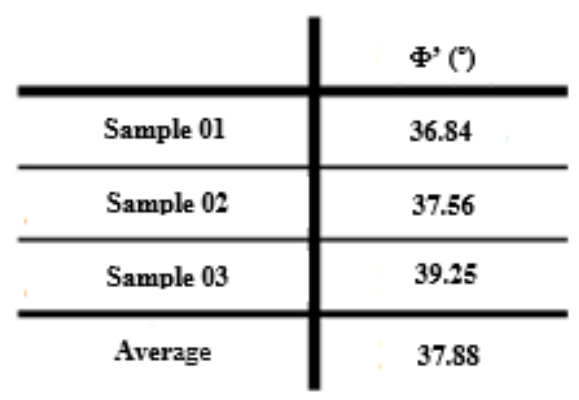

\subsection{Cohesion}

\subsubsection{CPTu}

Obtaining the cohesion intercept in CPTu tests is reduced to undrained shear resistance, since the test is mostly indicated and applied on soft soils. So, when performed in clay deposits, the test speed of $2 \mathrm{~cm} / \mathrm{s}$ ensures that it is being carried out in undrained conditions. Thus, for granular iron ore tailings, there are no results obtained for the effective cohesion intercept in the CPTu test.

\subsubsection{SPT}

Since the gradation test presented the studied soil as a sand, and according to the proposals made in the bibliographic review by Marangon (2006) [23] and Afonso (2016) [15], the value of the iron ore tailing effective cohesion is estimated as being null, that is, zero.

\subsubsection{Cu triaxial tests (consolidated undrained)}

From the data obtained in the triaxial tests performed on the three undisturbed samples collected, it was possible to trace the most adequate resistance envelope and obtain values for the effective cohesion intercept. After analysing the results of these tests, the average value of 0 $\mathrm{kPa}$ (zero) was registered for the cohesion intercept.

\subsection{Overview}

Table 3 below summarizes all the average, maximum and minimum information on shear strength obtained from the analysis of SPT, CPTu and laboratory tests (triaxial).

Table 3. Overview on the shear strength parameters

\begin{tabular}{c|c|c|c|c|c|c|c|c|c} 
& \multicolumn{3}{|c|}{ SPT } & \multicolumn{3}{c|}{ CPTu } & \multicolumn{3}{c}{ Laboratory } \\
\cline { 2 - 10 } & Aver. & Max. & Min. & Aver. & Max. & Min. & Aver. & Max. & Min. \\
\cline { 2 - 10 } Su $(\mathrm{kPa})$ & - & - & - & - & - & - & - & - & \\
\hline$\varphi^{\prime}\left({ }^{\circ}\right)$ & 31.08 & 55.77 & 20.22 & 35.50 & 48 & 30 & 37.88 & 39.25 & 36.84 \\
\hline $\mathrm{c}^{\prime}(\mathrm{kPa})$ & 0 & 0 & 0 & - & - & - & 0 & 0.01 & 0
\end{tabular}

\section{Conclusion}

The campaign of geotechnical tests carried out on the specific iron ore tailings of a certain company revealed parameters that meet what was proposed by several scholars regarding the shear strength parameters of this type of tailing.

In this way, the results of the resistance parameters presented in this document fit in the obtained values by bibliographies that studied iron ore tailings. It is concluded, therefore, the good applicability of CPTu, SPT and triaxial tests performed in the geotechnical investigation campaign presented here, as well as their importance when determining shear strength parameters that can serve as basic information for stability design and analysis .development.

In addition to the conclusions about the results obtained, its contribution is also highlighted, since it can serve as a database for other studies carried out on tailings and their resistance parameters.

\section{References}

1. Brazilian Mining Institute - IBRAM (2017). Anual report of activities. Brazilian Mining Association. Belo Horizonte, 2017.

2. A. Zhouri (2017). Mining, violence and resistance. An open field to knowledge development in Brazil. ed 1st. Marabá, PA. Iguana editorial.

3. E. S. Presotti (2002). The iron content influence on iron ore tailings resistance parameters. M.sc. essay, UFOP, Ouro Preto, MG, Brasil.

4. R. Chammas (2018). [personal message]. Received by < giovaniclrcosta@gmail.com> on December 2nd of 2018 . 
5. T. J. Espósito (2000). Observational and probabilistic methodology applied to tailings dams raised on hidraulic landfill. M.sc. essay, Civil and Enviromental Engineering Department, Universidade de Brasília, Brasília, DF, 363.

6. E. L. Pereira (2005). Potential liquefaction study on iron ore tailings under static loading. M.sc. essay, UFOP, Ouro Preto, MG, Brasil.

7. H. P. G. Motta (2008). Transitional tailing behaviour on geotechnical centrifuge. M.sc. essay, Coppe/URFJ, Rio de Janeiro, RJ, Brasil.

8. V. A. Rezende (2013). Study on a sandy tailing dam behaviour raised with the upstream method. M.sc. essay, Nugeo/UFOP, Ouro Preto, MG, Brasil.

9. G. D. Fredlund \& H. Rahardjo (1993). Soil mechanics for unsaturated soils. John Wiley \& Sons.

10. J. C. De Carvalho, G. De F. N. Gitirana Jr., S. L. Machado, M. M. dos A. Mascarenha, F. C. Silva Filho (2015). (Org). Solos Não Saturados no Contexto Geotécnico. ABMS.

11. ABNT- Associação Brasileira de Normas Técnicas (1991). NBR 12069/1991: Soil - In situ cone penetration test (cpt) - Test methodology. Rio de Janeiro.

12. P. K. Robertson \& Cabal (2015). Guide to cone penetration testing for geotechnical engineering. Gregg drilling \& testing inc. ed 6th. Singal Hill, California.

13. C. R. I. Clayton, M. C. Matthews, N. E. Simons (1995). Site investigation. Department of civil engineering, University of Surrey. ed 2nd.

14. F. Schnaid \& E. Odebrecht (2012). Field tests and their application to foundation engineering. ed $\mathbf{2 n d}$. Oficina de Textos editor, São Paulo.

15. A. F. G. Afonso (2016). Correlation between dynaminc penetration test and cone penetration test. 121. Essay (masters on construction engineering) Escola Superior de Tecnologia e Gestão of the Instituto Politécnico de Bragança, Bragança.

16. ABNT - Associação Brasileira de Normas Técnicas (2001). NBR 6484/2001: Soil - Simple recognition drilling with SPT - Test methodology. Rio de Janeiro.

17. P. W. Mayne, B. Christopher, J. Dejong (2002). Subsurface investigations - geotechnical site characterization, no. FHWA NHI-01-031. Washington, D.C.: Federal road administration, USA. Transport department.
18. B. M. Das (2011). Geotechnical engineering elements. Thomson learning. ed. 6th. São Paulo, SP.

19. B. A. Rigueira et al. (2015). Deformation and resistance parameters obtaining for a foundation soil from field and laboratory tests, with emphasis on the Ménard pressuremeter. 149. Research project (civil engineering bachelor) - Pontifícia Universidade Católica of Minas Gerais, Belo Horizonte.

20. C. De S. Pinto (2006). Soil mechanics basic course: in 16 classes. Oficina de Textos. ed 3rd. São Paulo, SP.

21. N. C. S. T. Passos (2009). Tailing dam: Geotechnical parameters evaluation on iron ore tailings from field tests - a case study. Curitiba, UFPR. (final course essay on civil engineering bachelor).

22. C. E. S. A. Filho (2010). Correlations for obtaining geotechnical parameters of compressible clays using light dynamic penetrometer. 127. Essay (mesters on geotechnics) - Universidade Federal de Ouro Preto, Ouro Preto.

23. M. Marangon (2006). Geotechnical and earth works topics - volume 1. Class notes on UFJF's civil engineering course. Juiz de Fora, MG.

24. K. Terzaghi \& R. B. Peck (1967). Soil mechanics in engineering practice. John Wiley e Sons. ed 2nd. New York, NY.

25. J. P. S. Silva (2014). Flow regime influence evaluation for the geotechnical behaviour in an upstream tailing dam. São Paulo, USP. (masters' essay on civil engineering).

26. A. H. Teixeira \& N. S. Godoy (1996). Analysis, project and execution on shallow foundations. In: Hachich et al. eds. Foundations: theory and practice. São Paulo, PINI. 7, 227-264.

27. T. Muromachi (1974). Phono-soundings apparatusdiscrimination of soil type by sound. Amsterdam, ESOPT-1. 2:1, 110-112.

28. M. Hatanaka \& A. Uchida (1996). Empirical correlation between penetration resistance and internal friction angle of sandy soils. Soils and foundations, vol. 36, no. 4, 1-9.

29. J. Sosnoski (2016). CPTu and DMT interpretation for intermediate permeability soils. 137. Essay (postgraduate in civil engineering) - Universidade Federal do Rio Grande do Sul, Porto Alegre. 